\title{
A DETERMINAÇÃO ESPECTROFOTOMÉTRICA DO COBALTO PELO MÉTODO DA 2,2'-DIPIRIDIL CETOXIMA (II)* - Escolha do solvente e estudos sobre a extração do composto
}

A.O. JACINTHO **

\section{RESUMO}

Foram continuados os estudos da parte experimental do método da 2,2'-dipiridil cetoxima, cuja finalidade é o estabelecimento de uma técnica adequada para a determinação do cobalto em material vegetal.

Estudos sobre o preparo, concentração e conservação do reativo, sobre a influência do $\mathrm{pH}$ na formação e extração do composto colorido e sobre o sistema tampão, já foram efetuados na etapa inicial.

Nesta oportunidade, procurou-se estudar o solvente; sua seleção, a sensibilidade, o tempo de extração, a inf́luência do contato entre as fases e a estabilidade da cor do composto.

\section{INTRODUÇÃO}

Segundo HOLLAND \& BOZIC (1968), o quelato formado pelo cobalto e a 2'2-dipiridil cetoxima, pode ser completamente extraido da fase aquosa, tanto pelo clorofórmio como pelo diclorometano. Indicaram também, que a extração do composto pelo álcool amílico, benzeno, acetato de etila, nitrobenzeno e tolueno, foi apenas parcial, enquanto que um tetracloreto de carbono, ciclo-hexano, éter dietílico, hexano e xileno, foi completamente ineficiente. Aqueles autores preferiram empregar o clorofórmio ao invés do diclorometano, devido a sua maior densidade e menor volatilidade e indicaram que naquele solvente o composto colorido apresentou um máximo de absorção a $388 \mathrm{~nm}$.

Com base nas condições já estabelecidas (JACINTHO, 1975a), no que se refere à concentração do reativo, condições de $\mathrm{pH}$ e sistema tampão, numa primeira fase do presente trabalho, além do clorofórmio e do diclorometano, outros solventes foram testados quanto à capacidade extrativa do quelato, a fim de se poder selecionar o mais adequado.

A seguir procurou-se analisar a sensibilidade do método e estabelecer as melhores condiçoes para a extração do composto colorido.

* Entregue para publicação em 9/10/1975. Trabalho realizado com auxílio da Fundação de Amparo à Pesquisa do Estado de São Paulo (FAPESP).

* Departamento de Química da E.S.A. "Luiz de Queiroz”, Piracicaba - SP. 


\section{MATERIAL E MÉTODOS}

\section{Escolha do solvente e estudos sobre a extrag̨å}

1. Seleção dos solventes - Os estudos foram conduzidos a partir de 6 e 10 microgramas de cobalto, em presença de 1,0 e.mg de $\mathrm{HCl}$ e de $10 \mathrm{ml}$ da solução tampão, a fim de simular as condições normais de aplicação do método.

Os solventes testados, juntamente com suas constantes físicas extraidas de MORRISON \& FREISER (1957) e WEAST et al. (1964), são apresentados a seguir.

Caracteristicas dos solventes testados:

\begin{tabular}{|c|c|c|c|c|}
\hline Solvente & $\begin{array}{l}\text { Densidade } \\
\text { a } 15 / 20^{\circ} \mathrm{C}\end{array}$ & $\begin{array}{l}\text { Ponto de } \\
\text { ebulição }\end{array}$ & $\begin{array}{l}\text { Constante } \\
\text { dielétrica }\end{array}$ & $\begin{array}{l}\text { Solubilidade } \\
\text { em água }\end{array}$ \\
\hline Clorofórmio & 1,49 & $61,2^{\circ} \mathrm{C}$ & 4,8 & $10 \mathrm{~g} / 1$ a $15^{\circ} \mathrm{C}$ \\
\hline Diclorometano & 1,34 & $40,1{ }^{\circ} \mathrm{C}$ & 9,1 & $20 \mathrm{~g} / 1$ a $20^{\circ} \mathrm{C}$ \\
\hline 1,2-dicloroetano & 1,26 & $83,6^{\circ} \mathrm{C}$ & 10,4 & $9 \mathrm{~g} / 1 \mathrm{a} \quad 0^{\circ} \mathrm{C}$ \\
\hline Monoclorobenzeno & 1,11 & $132,0^{\circ} \mathrm{C}$ & - & insolúvel \\
\hline o-diclorobenzeno & 1,30 & $180,5^{\circ} \mathrm{C}$ & 9,9 & insolúvel \\
\hline Metilisobutilcetona & 0,80 & $115,8^{\circ} \mathrm{C}$ & 13,1 & $20 \mathrm{~g} / 1$ a $20^{\circ} \mathrm{C}$ \\
\hline Acetato de amila & 0,87 & $149,2^{\circ} \mathrm{C}$ & 4,8 & $1,74 \mathrm{~g} / 1$ a $20^{\circ} \mathrm{C}$ \\
\hline Acetato de butila & 0,88 & $126,5^{\circ} \mathrm{C}$ & 5,0 & $5 \mathrm{~g} / 1$ a $25^{\circ} \mathrm{C}$ \\
\hline
\end{tabular}

Reativos:

Solução padrão de cobalto - A partir da solução estoque (JACINTHO, 1975a), foram preparadas soluções contendo $2,0-4,0-6,0-8,0$ e 10,0 ppm de cobalto.

Solução de 2,2'-dipiridil cetoxima (2,2'-DC) a 1,0\% - Preparada em solução hidroalcoólica a $80 \%$ a partir de 2,2 '-DC obtida conforme a técnica descrita por JACINTHO, (1975a).

Solução tampão - Foram misturados, $100 \mathrm{ml}$ de solução $1 \mathrm{M}$ em citrato de sódio (trissódico), com $50 \mathrm{ml}$ de solução de trietanolamina (1+2). Adicionou-se em seguida, a solução de ácido cítrico a $30 \%$, até pH 7,8 .

Solução 0,10 N em HCl - Preparada a partir de $6 \mathrm{~N}$ (destilado).

\section{Procedimento}

Em funis de separação de $60 \mathrm{ml}$, foram adicionados 6 e 10 microgramas de cobalto, $10 \mathrm{ml}$ da solução tampão, $10 \mathrm{ml}$ de solução $0,10 \mathrm{~N}$ em $\mathrm{HCl}, 1,0 \mathrm{ml}$ da solução do reativo e completou-se o volume a $20 \mathrm{ml}$. Adicionaram-se $5,0 \mathrm{ml}$ de cada um dos solventes já relacionados e procederam-se às extraçбes por dois minutos. As leituras foram efetuadas a $385 \mathrm{~nm}$ contra prova em branco e os resultados estão contidos no quadro 1 . 
2. Estudo comparativo entre o clorofórmio e o diclorometano - Apesar da menor solubilidade em água e do ponto de ebulição mais elevado apresentado pelo clorofórmio, procurou-se realizar um estudo comparativo entre o citado solvente e o diclorometano a fim de se obter um maior número de dados, através dos quais seria possivel uma adequada escolha.

Para tal, foram obtidas curvas padrão em clorofórmio e diclorometano, sendo também empregados diferentes volumes dos mesmos para as extraçбes. Através de uma segunda extração, foi testada a eficiência das mesmas.

A influência das diferentes solubilidades em água apresentada pelos dois solventes foi analisada pela comparação das curvas padrão obtidas em condiçбes de saturação e não saturação da fase aquosa. A fim de se poder analisar uma possivel influência do solvente sobre a região de máxima absorção do composto colorido, foram obtidos espectros do composto em clorofórmio e dicloronietano.

\section{Procedimento}

Em funis de separação de $60 \mathrm{ml}$, foram adicionados padrões de 2, 4, 6, 8 e 10 microgramas de cobalto e daqui por diante procedeu-se conforme já descrito em 1 . Utilizando a mesma técnica, novas curvas foram obtidas quando o composto foi extraído com 4,0 e 3,0 ml de solvente.

Após a primeira extração, a fase aquosa foi filtrada através de papel Whatman nọ 1 para outros funis de separação de $60 \mathrm{ml}$, para eliminar o solvente remanesicente. A seguir, adicionou-se mais $0,5 \mathrm{ml}$ do reativo e procederam-se a novas extraçōes com $3,0 \mathrm{ml}$ de solvente. Os resultados constam dos quadros 2 e 3 e figuras 1 e 2 .

Procurando-se analisar mais detalhadamente a influência da solubilidade em água apresentada pelos solventes em estudo, a solução tampão, a solução $0,10 \mathrm{~N} \mathrm{em} \mathrm{HCl} \mathrm{e} \mathrm{a}$ água, foram previamente saturados com clorofórmio ou com diclorometano. Novas curvas padrão foram obtidas, seguindo-se o mesmo procedimento. Os dados constam dos quadros 4 e 5 e também podem ser analisados nas figuras 1 e 2 .

Seguindo o procedimento descrito $2 \mathrm{~m} 1$, a partir de 6 e 10 microgramas de cobalto foram obtidos espectros de absorção do $\mathrm{Co}\left(2,2^{\prime}-\mathrm{DC}\right)_{3}$ em ambos os solventes, na região compreendida entre 480 e $320 \mathrm{~nm}$ de comprimento de onda e com auxílio do espectrofotômetro Beckman modelo DB. As curvas foram obtidas contra as respectivas provas em branco, as quais, por sua vez, foram analisadas contra solventes puros. Os resultados obtidos são apresentados nas figuras 3 e 4.

3. A sensibilidade do método - A determinação do cobalto em materiais contendo baixo teor do elemento como no caso dos vegetais, está sujeita a uma série de limitações. A sensibilidade apresentada pelos métodos mais comumente empregados com essa finalidade, exige o emprego de amostras relativ umente grandes dificultando sob vários aspectos as técnicas propostas.

Segundo os valores fornecidos por HOLLAND \& BOZIC (1968), a sensibilidade do método da 2,2'-DC conforme Sandell, é de 0,0029 micrograma $/ \mathrm{cm}^{2}$, sendo a absor- 
tividade molar do composto a. $388 \mathrm{~nm}$ de comprimento de onda, igual a 19.500 enquanto que para o método do sal nitroso-R, BAGREEV \& ZOLOTOV (1968) descreveram como sendo de 15.000 o valor da absortividade molar do composto no comprimento de onda de sua máxima absorção.

Considerando-se que uma das principais finalidades do presente estudo, é a de contribuir para o estabelecimento de uma técnica que apresente sensibilidade satisfatória para a determinação do cobalto em plantas, procurou-se analisar as possibilidades de se empregar menores quantidades do elemento, além de se extrair o composto, com volumes mais reduzidos de solvente.

Assim sendo, novas curvas padrão foram obtidas utilizando-se de 0,5 a 5,0 microgramas de cobalto, tendo sido seguido o procedimento já descrito em 2 . De igual modo, o composto foi extraído com 5,0 - 4,0 e 3,0 ml de clorofórmio e uma segunda extração foi procedida com $3,0 \mathrm{ml}$ do solvente. Com exceção das novas soluções padrão de uso, preparadas a partir da estoque, os demais reagentes já foram descritos. Os resultados são apresentados no quadro 6 e figura 5 .

4. Tempo de agitação necessário para a extração do composto - Para os experimentos até aqui realizados, as extrações do composto foram efetuadas com dois minutos de agitação manual e vigorosa. Considerando-se que uma redução no referido tempo pode representar uma melhoria nas condições operacionais do método, procurou-se através do presente ensaio, estabelecer tais condições.

HOLLAND \& BOZIC (1968), ao descreverem que trinta segundos de extração em $10 \mathrm{ml}$ de clorofórmio foram suficientes para remover todo composto da fase aquosa, deixam dúvidas quanto a quantidade do quelato em estudo.

Assim sendo, com os reagentes cujo preparo já foi descrito e seguindo-se o procedimento empregado em 1, desenvolveu-se o composto a partir de 4 e 5 microgramas de cobalto e procederam-se extrações com $3,0 \mathrm{ml}$ de clorofórmio por $15,30,60,90,120$ e 240 segundos. Os resultados constam do quadro 7.

5. Influência do tempo de contato entre as fases - Procurou-se nesta oportunidade, analisar a influência do tempo de contato entre as fases após a extração, sobre os valores de abso:bância da solução clorofórmica do composto.

$\mathrm{O}$ prccedimento descrito em 1 foi seguido com as seguintes modificações. $\mathrm{O}$ composto fo: obtido a partir de 3,0 e 5,0 microgramas de cobalto, sendo as extrações efetuadas por 30 segundos com $3,0 \mathrm{ml}$ do solvente. Após as extrações, as fases foram mantidas em contato nas condições ambiente $\left(20-25^{\circ} \mathrm{C}\right.$ e luz difusa) pelos tempos de 10 , 20, 30, 60 e 120 minutos. Decorridos os intervalos de tempo, efetuaram-se as leituras contra respectivas provas em branco. Os reagentes foram os mesmos já descritos e os resultados estão no quadro 8 .

6. Estabilidade da cor do composto em clorofórmio - HOLLAND \& BOZIC (1968) descreveram que os valores de absorbância das soluções do composto em clorofórmio, mantiveram-se inalterados por um período de 10 horas. Um decréscimo de $6 \%$ foi apreciado após duas semanas, não sendo observado variações nos referidos valores, em fun- 
ção das oscilações da temperatura ambiente.

Considerando-se que os dados sobre a estabilidade da cor do composto é de grande importância principalmente para a aplicação do método, com base no procedimento descrito em 1, desenvolveu-se a reação a partir de 3 e 5 microgramas de cobalto. Após as extrações com $3,0 \mathrm{ml}$ de clorofórmio, a fase orgânica foi drenada para células do espectrofotômetro. Os extratos foram mantidos em 3 diferentes condições:

A - em células hermeticamente fechadas (tampa de teflon) mantidas sob luz difusa (ambiente de laboratório), entre 20 e $25^{\circ} \mathrm{C}$;

B - em células com tampas de vidro (apenas superpostas) mantidas sob luz difusa, entre 20 e $25^{\circ} \mathrm{C}$;

C - em células com tampas de vidro, ao abrigo da luz e entre 20 e $25^{\circ} \mathrm{C}$.

Essas condições foram mantidas por 3 horas sendo as leituras efetuadas periodicamente contra respectivas provas em branco. Os reagentes utilizados foram os mesmos já descritos e os resultados são apresentados no quadro 9.

\section{RESULTADOS E DISCUSSÃO}

\section{Escolha do solvente e estudos sobre a extração}

1. Seleção dos solventes - Pelos valores de absorbância contidos no quadro 1 , pode-se concluir que dentre os solventes testados, apenas o clorofórmio e o diclorometano foram eficientes quanto à extração do quelato $\operatorname{Co}\left(2,2^{\prime}-\mathrm{DC}\right)_{3}$. Considerando-se os valores de absorbância obtidos com aqueles dois solventes, como representativos de uma extração $100 \%$ eficiente, pode-se dizer que o dicloroetano, o diclorobenzeno e o monoclorobenzeno extraíram $83 \%, 34 \%$ e $20 \%$ do composto, respectivamente. Os demais solventes testados não apresentaram a menor capacidade extrativa. Esse fato também foi observado com relação a tetracloreto de carbono e xileno em testes semiquantitativos.

Nessas condições, para os estudos seguintes foram utilizados apenas o clorofórmio e o diclorometano. 
QUADRO 1 - Avaliação da capacidade de extração do composto colorido pelos diversos solventes, através dos valores de absorbância do $\operatorname{Co}\left(2,2^{\prime}-\mathrm{DC}\right)_{3}$ em suas soluçōes (obtidas a partir de 6 e 10 microgramas de cobalto).

\begin{tabular}{lrc}
$\begin{array}{l}\text { Solvente } \\
(\mathrm{ml})\end{array}$ & $\begin{array}{c}\text { Microgramas } \\
\text { de cobalto }\end{array}$ & A \\
\hline \hline Clorofórmio & 6 & 0,36 \\
& 10 & 0,59 \\
Diclorometano & 6 & 0,36 \\
1,2-dicloroetano & 10 & 0,59 \\
& 6 & 0,30 \\
Monoclorobenzeno & 10 & 0,49 \\
& 6 & 0,07 \\
O-diclorobenzeno & 10 & 0,12 \\
& 6 & 0,12 \\
Metilisobutilcetona & 10 & 0,21 \\
& 6 & 0,00 \\
Acetato de amila & 10 & 0,01 \\
& 6 & 0,00 \\
Acetato de butila & 10 & 0,00 \\
& 6 & 0,00 \\
& 10 & 0,00 \\
\hline
\end{tabular}

2. Estudo comparativo entre o clorofórmio e o diclorometano - Pelos dados contidos nos quadros 2 e 3 representados nas figuras 1 e 2, observa-se que a relação é linear entre os valores de absorbância e as concentrações de cobalto, quer o extrator tenha sido o clorofórmio quer o diclorometano. Essa linearidade foi mantida mesmo quando as extrações foram efetuadas com 4,0 e 3,0 ml do solvente.

QUADRO 2 - Relação entre a absorbância e as quantidades de cobalto. Primeira e segunda extrações com clorofórmio. Fase aquosa não saturada.

\begin{tabular}{|c|c|c|c|c|c|c|}
\hline \multirow[b]{2}{*}{$\begin{array}{l}\text { Microgramas } \\
\text { de cobalto }\end{array}$} & \multicolumn{2}{|c|}{$5,0 \mathrm{ml}$ do solvente } & \multicolumn{2}{|c|}{$4,0 \mathrm{ml}$ do solvente } & \multicolumn{2}{|c|}{$3.0 \mathrm{ml}$ do solvente } \\
\hline & $\begin{array}{c}1 \mathfrak{a} \\
\text { extração }\end{array}$ & $\begin{array}{c}2 \mathrm{a} \\
\text { extração }\end{array}$ & $\begin{array}{c}\text { lạ } \\
\text { extração }\end{array}$ & $\begin{array}{c}2 \mathrm{a} \\
\text { extração }\end{array}$ & $\begin{array}{c}1 \mathrm{a} \\
\text { extração }\end{array}$ & $\begin{array}{c}2 \mathfrak{a} \\
\text { extração }\end{array}$ \\
\hline & A & A & A & A & A & A \\
\hline 0 & 0,00 & 0,00 & 0,00 & 0,00 & 0,00 & 0,00 \\
\hline 2 & 0,12 & 0,00 & 0,15 & 0,00 & 0,20 & 0,00 \\
\hline 4 & 0,24 & & 0,30 & & 0,40 & \\
\hline 6 & 0,36 & 0,00 & 0,45 & 0,00 & 0,59 & 0,01 \\
\hline 8 & 0,47 & & 0,60 & & 0,77 & \\
\hline 10 & 0,59 & 0,00 & 0,74 & 0,01 & 0,96 & 0,02 \\
\hline
\end{tabular}


QUADRO 3 - Relação entre a absorbância e as quantidades de cobalto. Primeira e segunda extrações com diclorometano. Fase aquosa não saturada.

\begin{tabular}{|c|c|c|c|c|c|c|}
\hline \multirow[b]{2}{*}{$\begin{array}{l}\text { Microgramas } \\
\text { de cobalto }\end{array}$} & \multicolumn{2}{|c|}{$5,0 \mathrm{ml}$ do solvente } & \multicolumn{2}{|c|}{$4,0 \mathrm{ml}$ do solvente } & \multicolumn{2}{|c|}{$3,0 \mathrm{ml}$ do solvente } \\
\hline & $\begin{array}{c}1 \stackrel{a}{a} \\
\text { extração }\end{array}$ & $\begin{array}{c}2 \mathfrak{a} \\
\text { extração }\end{array}$ & $\begin{array}{c}1 \mathrm{a} \\
\text { extração }\end{array}$ & $\begin{array}{c}2 \mathfrak{a} \\
\text { extração }\end{array}$ & $\begin{array}{c}\text { 1ạ } \\
\text { extração }\end{array}$ & $\begin{array}{c}2 \mathrm{a} \\
\text { extração }\end{array}$ \\
\hline & A & $\mathbf{A}$ & A & A & $\overline{\mathrm{A}}$ & $\overline{\mathrm{A}}$ \\
\hline 0 & 0,00 & 0,00 & 0,00 & 0,00 & 0,00 & 0,00 \\
\hline 2 & 0,12 & 0,00 & 0,15 & 0,01 & 0,21 & 0,02 \\
\hline 4 & 0,24 & & 0,30 & & 0,39 & \\
\hline 6 & 0,36 & 0,02 & 0,44 & 0,03 & 0,58 & 0,06 \\
\hline 8 & 0,47 & & 0,58 & & 0,77 & \\
\hline 10 & 0,59 & 0,04 & 0,72 & 0,05 & 0,94 & 0,07 \\
\hline
\end{tabular}

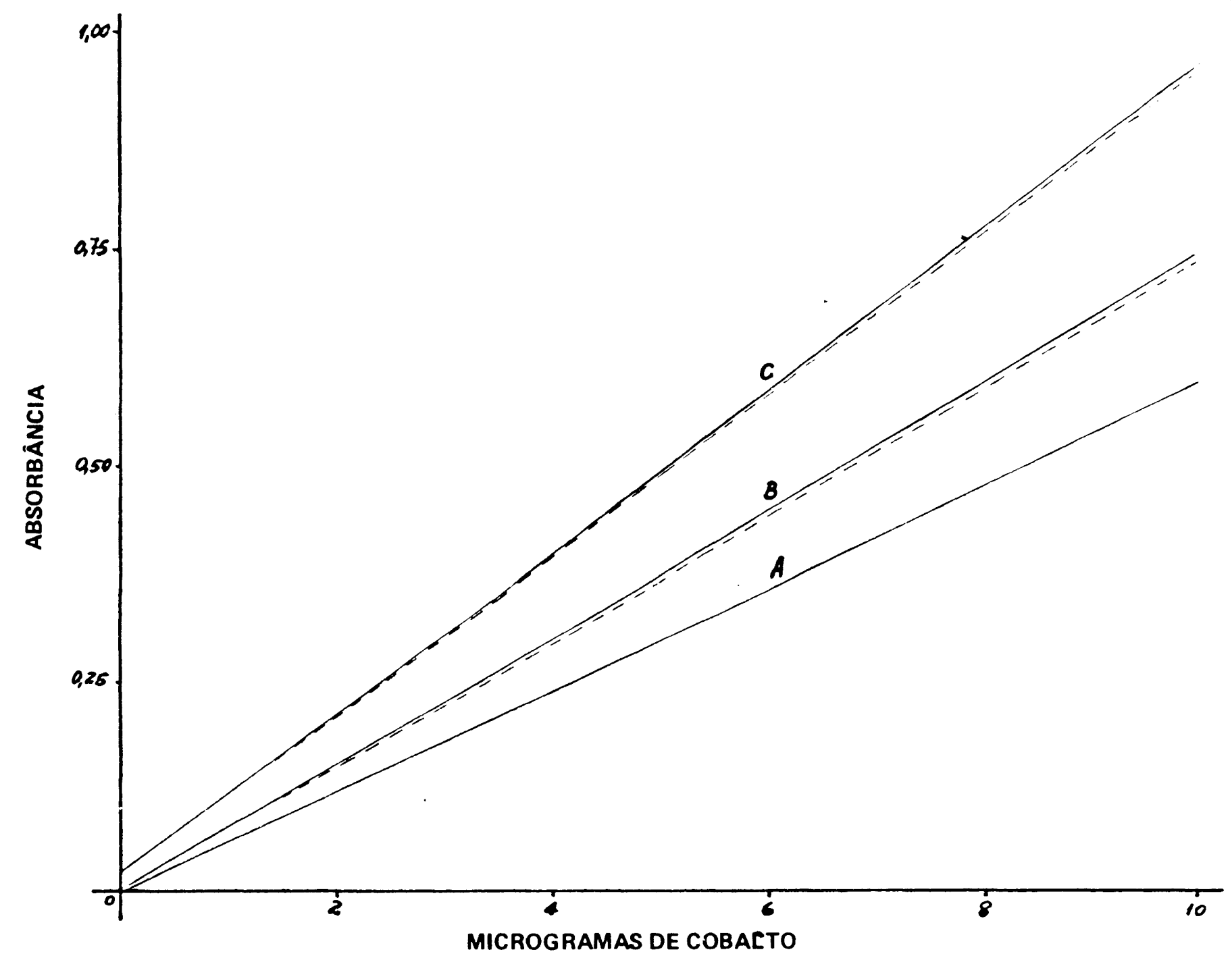

FIG. 1 - Relação entre absorbância e quantidades de cobalto. Extração com 3,0 ml (curva C), $4,0 \mathrm{ml}$ (curva B) e $5,0 \mathrm{ml}$ (curva A) de clorofórmio. Linha cheia - não saturando a fase aquosa. Linha pontilhada - saturando a fase aquosa. 


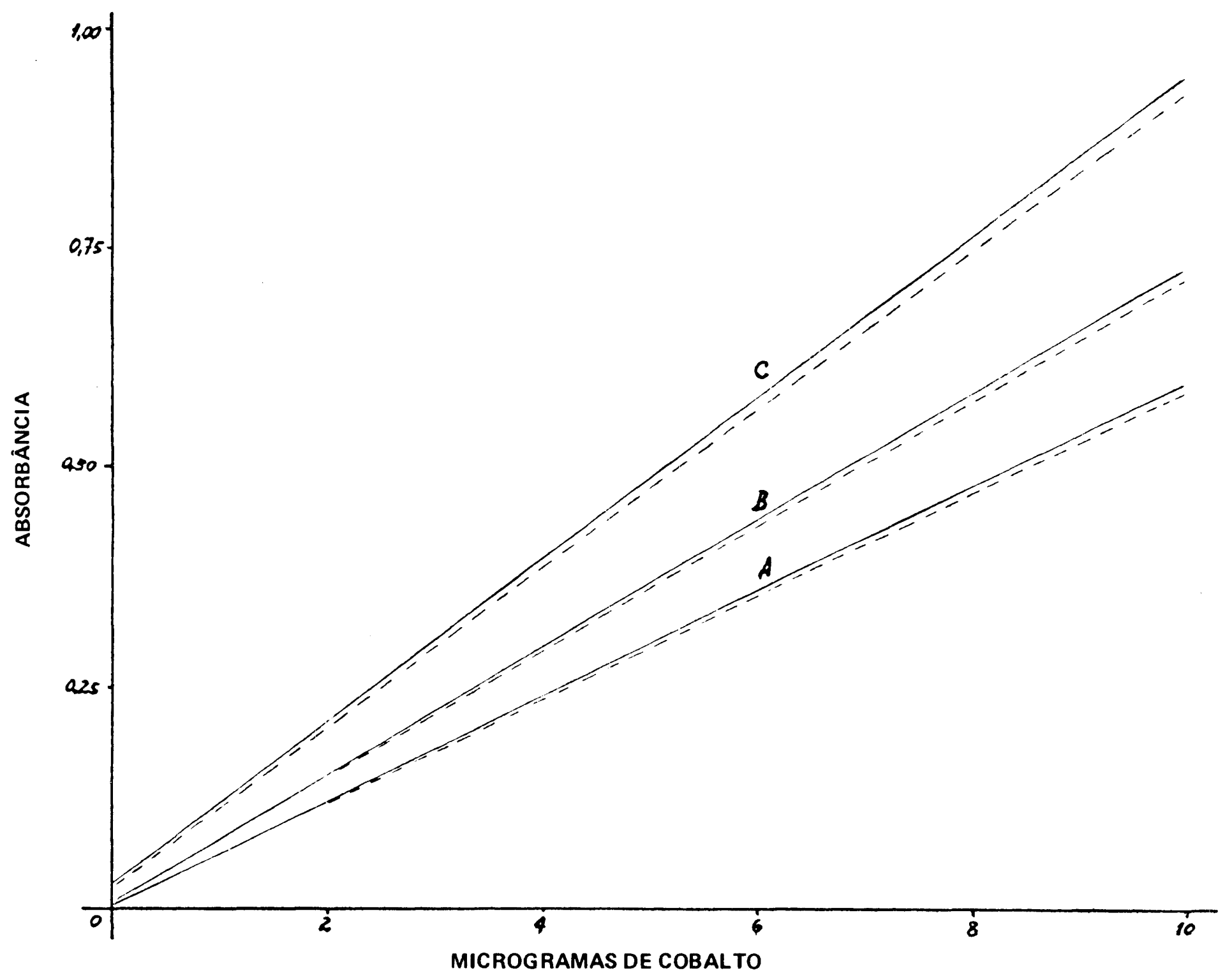

FIG. 2 - Relação entre absorbância e quantidades de cobalto. Extração com 3,0 ml (curva C), 4,0 ml (curva B) e 5,0 ml (curva A) de diclorometano. Linha cheia - não saturando a fase aquosa. Linha pontilhada - saturando a fase aquosa.

Comparando-se os dados dos quadros 2 e 3, pode-se verificar a menor eficiência extrativa apresentada pelo diclorometano. Isto é, enquanto que $4,0 \mathrm{ml}$ de clorofórmio foram suficientes para remover da fase aquosa todo o composto obtido com até $10 \mathrm{mi}$ crogramas de cobalto, $5,0 \mathrm{ml}$ de diclorometano não o foram.

A sensibilidade conferida ao método foi praticamente equivalente tanto empregando-se o clorofórmio como o diclorometano.

$\mathrm{O}$ efeito da maior solubilidade em água, apresentado pelo diclorometano, pode ser melhor observado através das figuras 1 e 2 . Isto é, com o referido solvente, as diferenças obtidas nos valores de absorbância quando a fase aquosa foi ou não saturada pelo mesmo antes das extrações, foram maiores que aquelas obtidas com o clorofórmio. 
Uma comparação entre os dados dos quadros $2,3,4$ e 5 mostra que a diminuição da capacidade de extração do composto, após a saturação da fase aquosa, foi mais pronunciada para o diclorometano.

QUADRO 4 - Relação entre a absorbância e as quantidades de cobalto. Primeira e segunda extrações com clorofórmio. Fase aquosa saturada.

\begin{tabular}{|c|c|c|c|c|c|c|}
\hline \multirow[b]{2}{*}{$\begin{array}{c}\text { Microgramas } \\
\text { de cobalto }\end{array}$} & \multicolumn{2}{|c|}{$5,0 \mathrm{ml}$ do solvente } & \multicolumn{2}{|c|}{$4,0 \mathrm{ml}$ do solvente } & \multicolumn{2}{|c|}{$3,0 \mathrm{ml}$ do solvente } \\
\hline & $\begin{array}{c}\text { ạ } \\
\text { extra̧ãão }\end{array}$ & $\begin{array}{c}2 \mathrm{a} \\
\text { extra̧ãão }\end{array}$ & $\begin{array}{c}\text { ạa } \\
\text { extração }\end{array}$ & $\begin{array}{c}2 \mathrm{a} \\
\text { extração }\end{array}$ & $\begin{array}{c}1 \text { ạ } \\
\text { extra̧ãa }\end{array}$ & $\begin{array}{c}2 \mathrm{a} \\
\text { extração }\end{array}$ \\
\hline & A & A & A & A & A & A \\
\hline 0 & 0,00 & 0,00 & 0,00 & 0,00 & 0,00 & 0,00 \\
\hline 2 & 0,12 & 0,00 & 0,15 & 0,00 & 0,21 & 0,00 \\
\hline 4 & 0,24 & & 0,29 & & 0,39 & \\
\hline 6 & 0,36 & 0,00 & 0,44 & 0,01 & 0,59 & 0,01 \\
\hline 8 & 0,47 & & 0,59 & & 0,76 & \\
\hline 10 & 0,59 & 0,00 & 0,73 & 0,01 & 0,95 & 0,02 \\
\hline
\end{tabular}

QUADRO 5 - Relação entre a absorbância e as quantidades de cobalto. Primeira e segunda extrações com diclorometano. Fase aquosa saturada.

\begin{tabular}{|c|c|c|c|c|c|c|}
\hline \multirow{2}{*}{$\begin{array}{l}\text { Microgramas } \\
\text { de cobalto }\end{array}$} & \multicolumn{2}{|c|}{$5,0 \mathrm{ml}$ do solvente } & \multicolumn{2}{|c|}{$4,0 \mathrm{ml}$ do solvente } & \multicolumn{2}{|c|}{$3,0 \mathrm{ml}$ do solvente } \\
\hline & $\begin{array}{c}1 \mathfrak{a} \\
\text { extração }\end{array}$ & $\begin{array}{c}2 \mathrm{a} \\
\text { extração }\end{array}$ & $\begin{array}{c}1 \mathfrak{a} \\
\text { extração }\end{array}$ & $\begin{array}{c}2 \mathrm{a} \\
\text { extração }\end{array}$ & $\begin{array}{c}1 \mathrm{a} \\
\text { extração }\end{array}$ & $\begin{array}{c}2 \underset{\mathrm{a}}{ } \\
\text { extração }\end{array}$ \\
\hline & A & A & A & A & A & A \\
\hline 0 & 0,00 & 0,00 & 0,00 & 0,00 & 0,00 & 0,00 \\
\hline 2 & 0,12 & 0,01 & 0,15 & 0,01 & 0,20 & 0,02 \\
\hline 4 & 0,23 & & 0,29 & & 0,38 & \\
\hline 6 & 0,35 & 0,03 & 0,43 & 0,04 & 0,57 & 0,05 \\
\hline 8 & 0,46 & & 0,57 & & 0,74 & \\
\hline 10 & 0,58 & 0,06 & 0,71 & 0,07 & 0,92 & 0,10 \\
\hline
\end{tabular}

Pode ser observado pelas figuras 3 e 4 que nas condições estudadas, tanto em clorofórmio como em diclorometano, a região de máxima absorção do composto situou-se entre 375 e $390 \mathrm{~nm}$. Pode-se verificar também que, na citada região, a absorção devida à prova em branco, foi em ambos os casos, praticamente desprezível. Em função dos dados obtidos, confirmou-se a escolha do clorofórmio como solvente. 


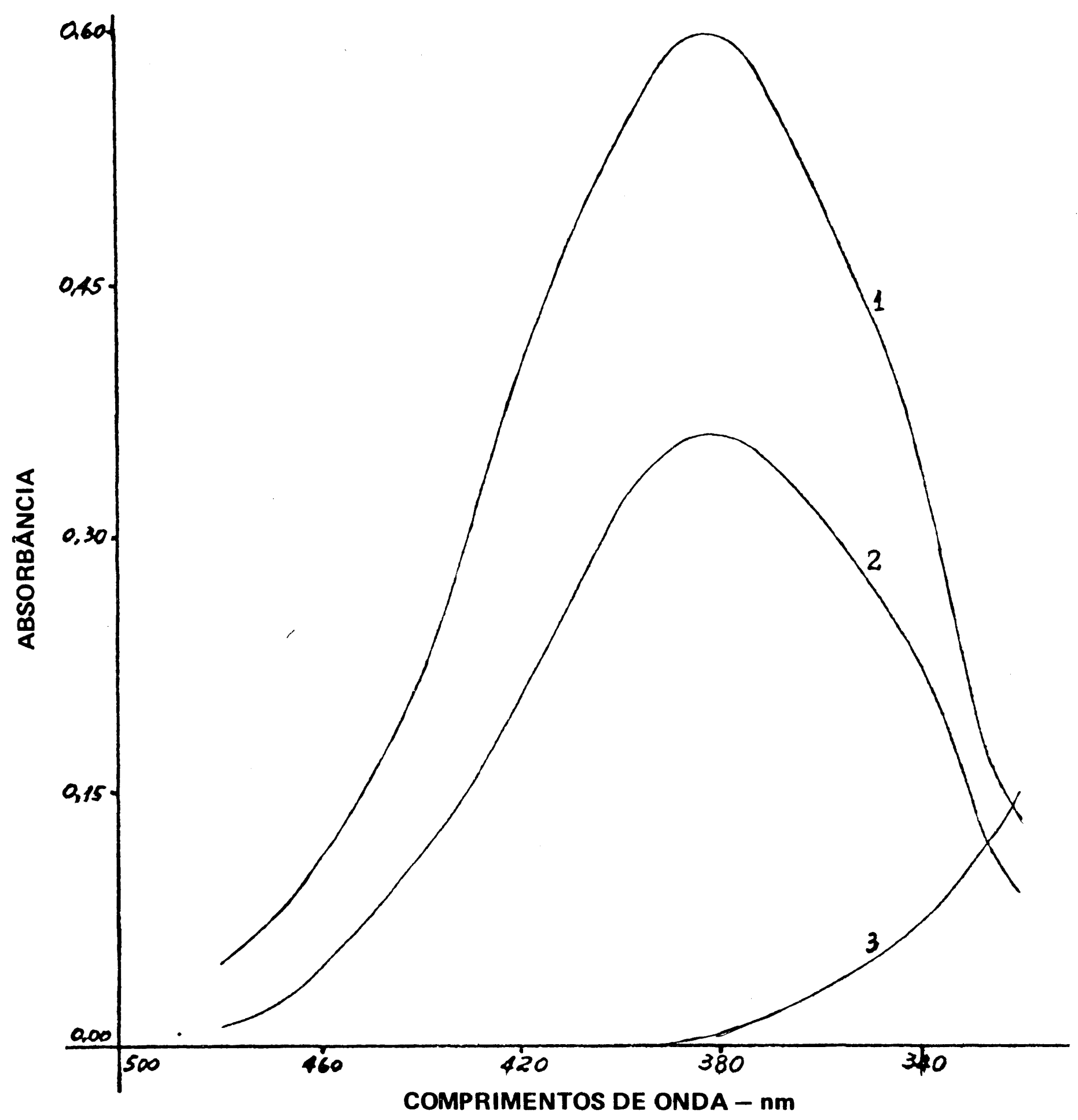

FIG. 3 - Espectros de absorção do composto colorido extraído com $5,0 \mathrm{ml}$ de clorofórmio. Curva 1 - $10 \mu \mathrm{g}$ de cobalto. Curva $2-6 \mu \mathrm{g}$ de cobalto. Curva 3 - Espectro branco contra 0 solvente puro. 


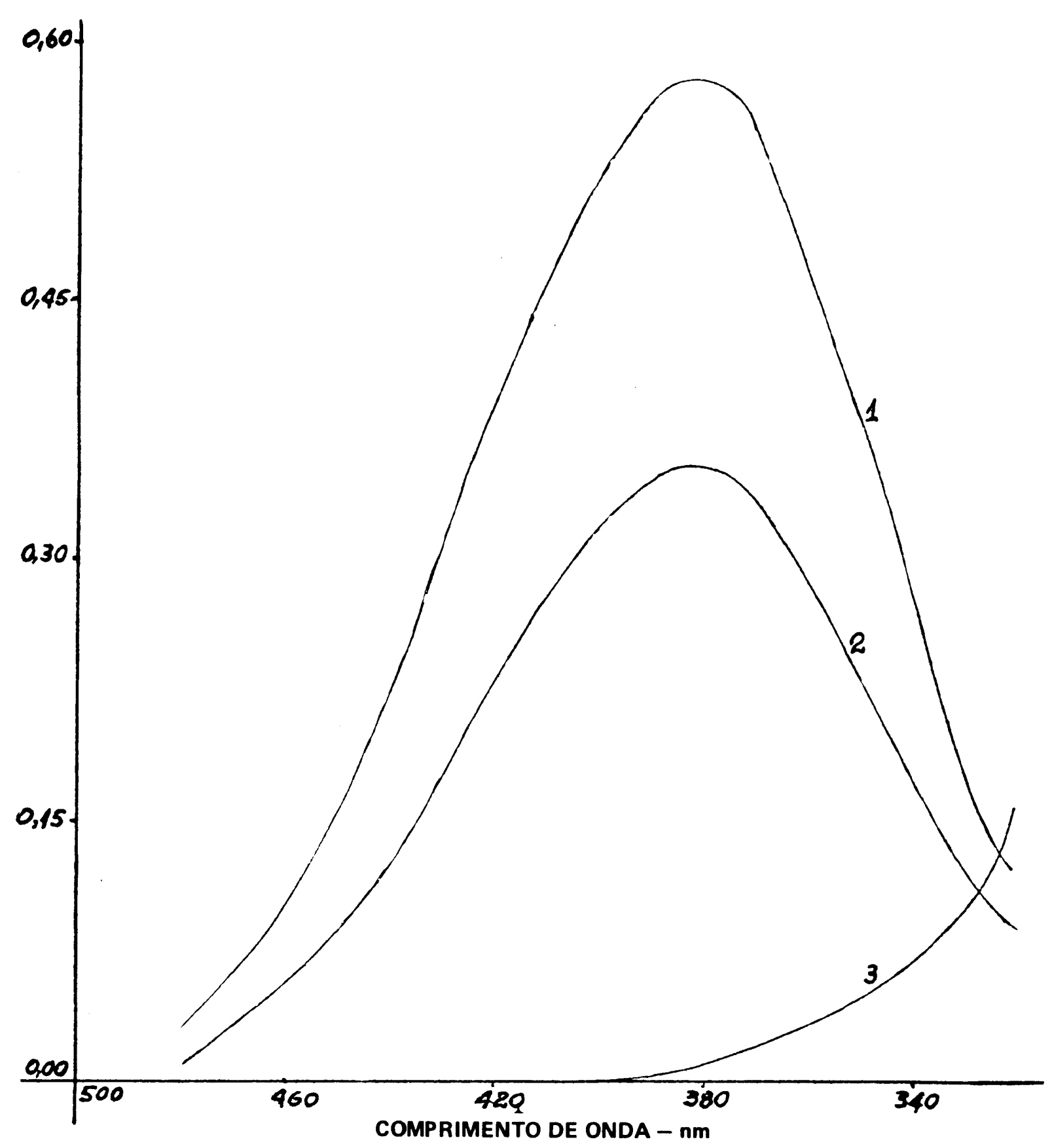

FIG. 4 - Espectros de absorção do composto colorido extraído com 5,0 $\mathrm{ml}$ de diclorometano. Curva $1-10 \mu \mathrm{g}$ de cobalto. Curva $2-6 \mu \mathrm{g}$ de cobalto. Curva 3 - Espectro do branco contra o solvente puro. 
3. A sensibilidade do método - Os valores apresentados no quadro 6, graficamente relacionados na figura 5 , indicam que para as quantidades de cobalto estudadas, a relação linear entre a absorbância e a concentração foi mantida, quer o composto tenha sido extraído com $5,0-4,0$ ou $3,0 \mathrm{ml}$ de clorofórmio. Os valores de absorbância referentes à segunda extração indicaram que apenas uma extração com até $3,0 \mathrm{ml}$ do solvente, foi suficiente para remover da fase aquosa, as quantidades obtidas do composto.

QUADRO 6 - Relação entre a absorbância e as quantidades de cobalto (de 0,5 a 5,0 microgramas). Primeira e segunda extrações com clorofórmio, sem saturar a fase aquosa.

\begin{tabular}{|c|c|c|c|c|c|c|}
\hline \multirow[b]{2}{*}{$\begin{array}{l}\text { Microgramas } \\
\text { de cobalto }\end{array}$} & \multicolumn{2}{|c|}{$5,0 \mathrm{ml}$ do solvente } & \multicolumn{2}{|c|}{$4,0 \mathrm{ml}$ do solvente } & \multicolumn{2}{|c|}{$3,0 \mathrm{ml}$ do solvente } \\
\hline & $\begin{array}{c}1 \mathrm{a} \\
\text { extração }\end{array}$ & $\begin{array}{c}2 \mathrm{a} \\
\text { extração }\end{array}$ & $\begin{array}{c}1 \mathrm{a} \\
\text { extração }\end{array}$ & $\begin{array}{c}2 \mathrm{a} \\
\text { extração }\end{array}$ & $\begin{array}{c}1 \mathrm{a} \\
\text { extração }\end{array}$ & $\begin{array}{c}2 \mathrm{a} \\
\text { extração }\end{array}$ \\
\hline & A & A & A & A & A & A \\
\hline 0,0 & 0,00 & 0,00 & 0,00 & 0,00 & 0,00 & 0,00 \\
\hline 0,5 & 0,03 & & 0,04 & & 0,05 & \\
\hline 1,0 & 0,06 & & 0,08 & & 0,10 & \\
\hline 2,0 & 0,12 & & 0,15 & & 0,20 & \\
\hline 3,0 & 0,18 & 0,00 & 0,23 & 0,00 & 0,30 & 0,00 \\
\hline 4,0 & 0,24 & 0,00 & 0,30 & 0,00 & 0,40 & 0,00 \\
\hline 5,0 & 0,30 & 0,00 & 0,38 & 0,00 & 0,50 & 0,01 \\
\hline
\end{tabular}

Através da figura 5, pode-se observar melhor o considerável aumento de sensibilidade que foi conferido ao método, quando a extração se processou com $3,0 \mathrm{ml}$ de clorofórmio. 


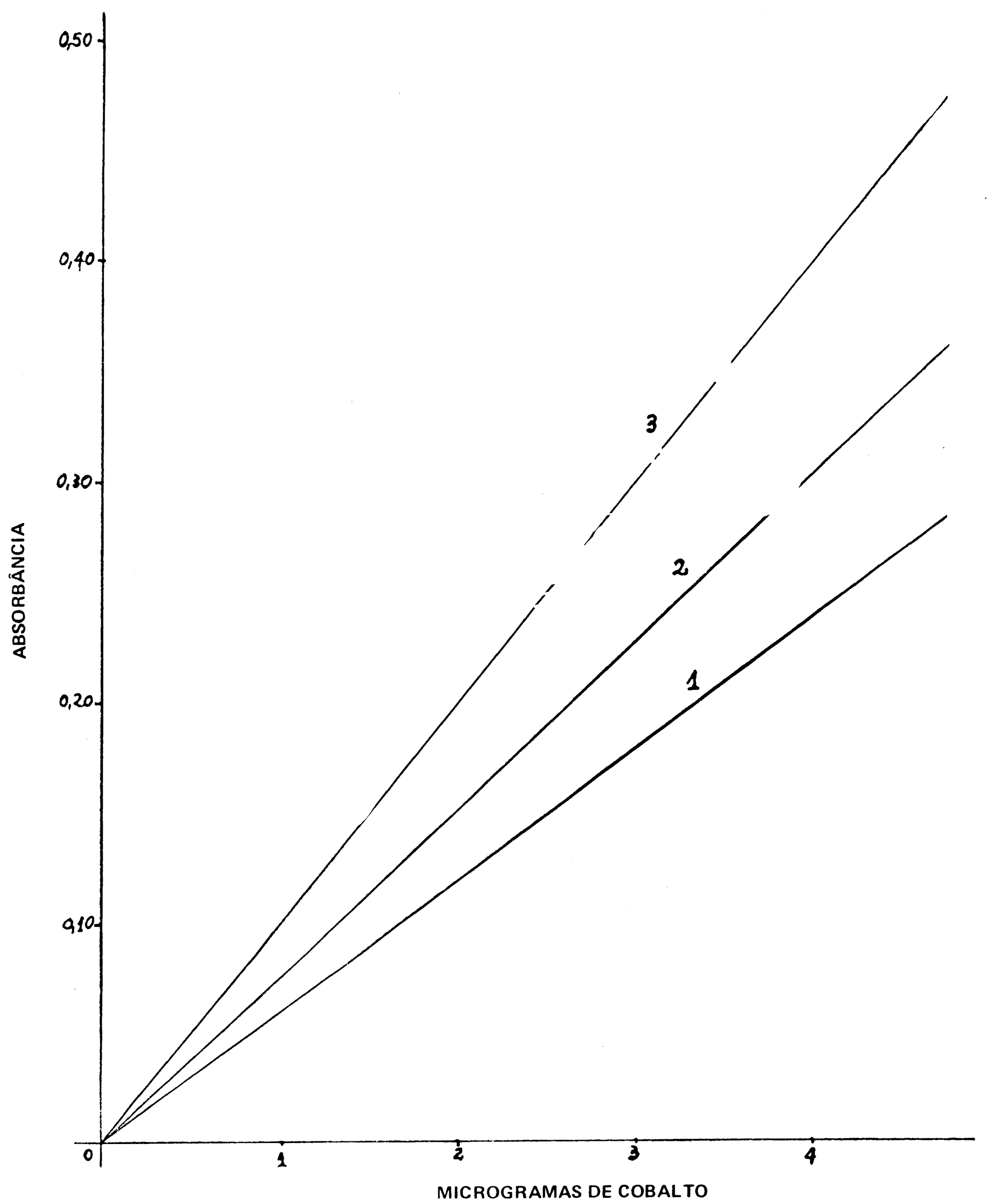

FIG. 5 - Relação entre a absorbân : ‘ e quantidades de cobalto. Extração com 3,0 ml (curva 3), $4,0 \mathrm{ml}$ (curva 2) e 5,0 ml v va 1) de clorofórmio. Fase aquosa não saturada com o solvente. 
4. Tempo de agitação necessário para a extração do composto - Os dados do quadro 7 revelam que a extração foi completa com 15 segundos de agitação. Porém, como medida de segurança, resolveu-se recomendar o tempo de 30 segundos.

QUADRO 7 - Influência do tempo de agitação na extração do composto colorido com $3,0 \mathrm{ml}$ do solvente e obtido a partir de 4,0 e 5,0 microgramas de cobalto.

\begin{tabular}{ccccccc}
\hline $\begin{array}{c}\text { Microgramas } \\
\text { de cobalto }\end{array}$ & 15 & 30 & 60 & 90 & 120 & 240 \\
\hline \hline & A & A & A & A & A & A \\
0,0 & 0,00 & 0,00 & 0,00 & 0,00 & 0,00 & 0,00 \\
4,0 & 0,40 & 0.40 & 0,40 & 0,40 & 0,39 & 0,40 \\
5,0 & 0,50 & 0,50 & 0,50 & 0,49 & 0,50 & 0,50 \\
\hline
\end{tabular}

5. Influência do tempo de contato entre as fases - Os dados do quadro 8 mostram a inexistência de qualquer efeito devido ao contato entre as fases (até 2 horas) após a extração, sobre os valores de absorbância das soluçc̃es.

QUADRO 8 - Valores de absorbância das soluções contendo o composto colorido, em função do tempo de contato entre as fases após a extração.

\begin{tabular}{ccccccc}
\hline \multirow{2}{*}{$\begin{array}{c}\text { Microgramas } \\
\text { de cobalto }\end{array}$} & \multicolumn{6}{c}{ Tempo de contato entre as tases após extração (em minutos) } \\
\cline { 2 - 6 } & 0 & 10 & 20 & 30 & 60 & 120 \\
\hline \hline & $\mathrm{A}$ & $\mathrm{A}$ & $\mathrm{A}$ & $\mathrm{A}$ & $\mathrm{A}$ & $\mathrm{A}$ \\
0,0 & 0,00 & 0,00 & 0,00 & 0,00 & 0,00 & 0,00 \\
3,0 & 0,30 & 0,30 & 0,30 & 0,30 & 0,30 & 0,30 \\
5,0 & 0,50 & 0,49 & 0,50 & 0,50 & 0,50 & 0,50 \\
\hline
\end{tabular}

6. Estabilidade da cor do composto em clorofórmio - 0 aumento nos valores de absorbância para as condições $\mathrm{B}$ e $\mathrm{C}$ a partir de 120 minutos (quadro 9), deve-se à evaporação de parte do solvente. Nota-se também que para um período de até 3 horas, a cor do comrosto em clorofórmio manteve-se estável. 
QUADRO 9 - Variação nos valores de absarbância da solução contendo o composto colorido, em função do tempo e das diferentes condições estudadas.

\begin{tabular}{|c|c|c|c|c|c|c|c|c|}
\hline \multirow{2}{*}{$\begin{array}{l}\text { Condições } \\
\text { estudadas }\end{array}$} & \multirow{2}{*}{$\begin{array}{l}\text { Microgramas } \\
\text { de cobalto }\end{array}$} & \multicolumn{7}{|c|}{ Tempo em minutos } \\
\hline & & $\mathbf{0}$ & 15 & 30 & 60 & 120 & 150 & 180 \\
\hline & & A & A & A & A & A & A & $\mathbf{A}$ \\
\hline $\mathbf{A}$ & $\begin{array}{l}0,0 \\
3,0 \\
5,0\end{array}$ & $\begin{array}{l}0,00 \\
0,30 \\
0,50\end{array}$ & $\begin{array}{l}0,00 \\
0,30 \\
0,50\end{array}$ & $\begin{array}{l}0,00 \\
0,30 \\
0,50\end{array}$ & $\begin{array}{l}0,00 \\
0,30 \\
0,50\end{array}$ & $\begin{array}{l}0,00 \\
0,30 \\
0,50\end{array}$ & $\begin{array}{l}0,00 \\
0,30 \\
0,50\end{array}$ & $\begin{array}{l}0,00 \\
0,30 \\
0,50\end{array}$ \\
\hline B & $\begin{array}{l}0,0 \\
3,0 \\
5,0\end{array}$ & $\begin{array}{l}0,00 \\
0,30 \\
0,50\end{array}$ & $\begin{array}{l}0,00 \\
0,30 \\
0,50\end{array}$ & $\begin{array}{l}0,00 \\
0,30 \\
0,50\end{array}$ & $\begin{array}{l}0,00 \\
0,30 \\
0,50\end{array}$ & $\begin{array}{l}0,00 \\
0,30 \\
0,50\end{array}$ & $\begin{array}{l}0,00 \\
0,31 \\
0,51\end{array}$ & $\begin{array}{l}0,00 \\
0,32 \\
0,53\end{array}$ \\
\hline C & $\begin{array}{l}0,0 \\
3,0 \\
5,0\end{array}$ & $\begin{array}{l}0,00 \\
0,30 \\
0,50\end{array}$ & $\begin{array}{l}0,00 \\
0,30 \\
0,501\end{array}$ & $\begin{array}{l}0,00 \\
0,30 \\
0,50\end{array}$ & $\begin{array}{l}0,00 \\
0,30 \\
0,50\end{array}$ & $\begin{array}{l}0,00 \\
0,30 \\
0,50\end{array}$ & $\begin{array}{l}0,00 \\
0,31 \\
0,51\end{array}$ & $\begin{array}{l}0,00 \\
0,32 \\
0,52\end{array}$ \\
\hline
\end{tabular}

\section{CONCLUSŌES}

Através dos estudos efetuados no presente trabalho, correspondentes à segunda fase da parte experimental do método espectrofotométrico da 2,2'-dipiridil cetoxima, pode-se concluir:

a - dos solventes escolhidos para o estudo, foram selecionados apenas o clorofórmio e o diclorometano;

b - num estudo comparativo entre aqueles dois solventes, o clorofórmio apresentou uma maior capacidade extrativa que a do diclorometano. Com $4,0 \mathrm{ml}$ de clorofórmio, extraiu-se da fase aquosa todo o composto colorido obtido a partir de $10 \mathrm{mi}$ crogramas de cobalto;

c - tanto em clorofórmio como em diclorometano, a região de máxima absorção do composto ocorreu entre 375 e $390 \mathrm{~nm}$;

d - numa amplitude de 0,5 a 5,0 microgramas de cobalto, $3,0 \mathrm{ml}$ de clorofórmio foram suficientes para a total extração do composto, com um acréscimo na sensibilidade do método;

e - 15 segundos de agitação foram suficientes para que a extração se completasse;

f - não foi notada qualquer influência decorrente do contato entre as fases, até 120 minutos após a extração;

g - a estabilidade da cor do composto em clorofórmio, foi mantida em 180 minutos de observações, após a extração. 


\section{SUMMARY}

SPECTROPHOTOMETRIC DETERMINATION OF COBALT BY THE 2,2'-DIPYRIDIL KETOXIME METHOD (II) - Choice of solvent and studies about colored compound extration

This paper belongs to a series of articles about the 2,2'-dipyridyl ketoxime method for the espectrophotometric determination of cobalt.

It presents a study on the extration procedure of the color compound formed by using chloroform or dichloromethane. It was established that the former is more efficient than the latter one.

The region of maximum absorption of the color compound in chloroform is between 375 and $390 \mathrm{~nm}$. On the other hand, $3.0 \mathrm{ml}$ of the solvent, is sufficient for the extration of the water-soluble chelate obtained from 5.0 micrograms of cobalt, with a shaking time of 15 seconds.

The color compound is stabile both in contact with the solutions (120 minutes) and after extration with chloroform (180 minutes).

\section{LITERATURA CITADA}

BAGREEV, V.V. \& ZOLOTOV, Y.A., 1968. Extractive photometric determination of cobalt with acid monochrome green $S$. Talanta, vol. 15:988-991.

HOLLAND, W.J. \& BOZIC, J., 1968. Rapid spectrophotometric determination of cobalt with 2,2'-dipyridyl ketoxime. Talanta, $15: 843-847$.

JACINTHO, A.O., 1975a. A determinação espectrofotométrica do cobalto pelo método da 2,2'dipiridil cetoxima (I). No prelo dos Anais da E.S.A. "Luiz de Queiroz", vol. 32. (1975).

MORRISON, G.H. \& FREISER, H., 1957. Solvent Extraction in Analytical Chemistry. New York. John Wiley \& Sons, 269 p.

WEST, R.C., SELBY, S.M. \& HODGMAN, C.D., 1964. Handbook of Chemistry and Physics. Published by The Chemical Rubber Co. Cleveland, Ohio. 